J. Clin. Chem. Clin. Biochem.

Vol. 20, 1982, pp. 627-632

\title{
Zur Bestimmung der katalytischen Aktivität der Lipase mit 8-Phenyloctansäure-vinylester als Substrat
}

Von W. Rick und $M$. Hockeborn

Institut für Klinische Chemie und Laboratoriumsdiagnostik der Universität Düsseldorf

(Eingegangen am 25 September/14. Dezember 1981)

Zusammenfassung: Der von Myrick ((1976) Ph. D. Thesis, Birmingham AL, U.S.A.) beschriebene UV-Test zur Bestimmung der katalytischen Aktivität der Lipase im Serum mit 8-Phenyloctansäure-vinylester als Substrat wurde eingehend geprüft. Die Reaktion zeigte bei Einsatz von Seren keine ausreichende Linearität. Bei einem Teil der untersuchten Proben war eine Auswertung wegen nicht geradlinigen Ablaufs unmöglich. Nicht nur gereinigte Lipase, aus Pankreas, sondern auch Esterase aus Leber, Cholinesterase aus Plasma und Lipoproteinlipase setzen das Substrat um. Versuche zur Hemmung der störenden Esterasen mit Phenylmethylsulfonylfluorid schlugen fehl. An 102 Seren wurde keine Korrelation mit den Resultaten des titrimetrischen Tests gefunden $(r=0,158)$. Somit ist es verständlich, daß die Methode von Myrick keine klinisch relevanten Aussagen erlaubt.

\section{Determination of lipase with 8-phenyloctanoic acid vinyl ester as substrate}

Summary: The UV-test described by Myrick ((1976) $\mathrm{Ph}$. D. Thesis, Birmingham, AL, USA) for the determination of the catalytic activity of lipase in serum, using 8-phenyloctanoic acid vinyl ester as substrate, was investigated in detail. When tested with sera the assay gave unsatisfactory linearity. For some serum samples, evaluation was impossible, owing to the complete lack of a linear response. The substrate is attacked not only by purified pancreatic lipase, but also by liver esterase, cholinesterase in plasma, and lipoproteinlipase. Attempts to inhibit the interfering esterases with phenylmethylsulphonylfluoride were unsuccessful. Analyses of 102 sera showed no correlation with the results from the titrimetric assay $(\mathrm{r}=0.158)$. Thus the method of Myrick does not provide clinically useful results.

\section{Einführung}

Die katalytische Aktivität der Lịpase (Triacylglycerol acyl hydrolase, EC 3.1.1.3) kann bisher nur mit Triglyceriden langkettiger Fettsäuren als Substrat spezifisch bestimmt werden. Das auf der kontinuierlichen $\mathrm{T} i$ tration der aus einer Triolein-Emulsion freigesetzten Fettsäuren beruhende Verfahren (1) erfordert, wenn die im Serum vorhandenen geringen kătalytischen Aktivitäten exakt gemesșen werdẹn sollen, außerordentliche Sorgfalt und einen erheblichen apparativen sowie zeitlichen Aufwand (2). Daher hat es nicht an Vèrsuchen gefehlt, einfachere - vor allem photometrische - Verfahren zur Messung der Lipase zu entwickeln (3). 1976 beschrieb Myrick (4) einen optischen Test mit 8-Phenyloctansäurevinylester als Substrat und mit Alkoholdehydrogenase als Hilfsenzym, der wesentlich geringere Ansprüche an die apparative Ausstattung und die technische Ausführung stellt. Wir prüften daher das neue Verfahren und analysierten gereinigte Enzyme sowie Seren von Gesunden bzw. Pankreatitispatienten, um insbesondere Aussagen zur Spezifität machen zu können.

\section{Material}

Enzyme

Die folgenden Enzympräparationen wurden eingesetzt:

Lipase (Triacylglycerol acyl hydrolase, EC 3.1.1.3), gereinigte Pankreaslipase aus menschlichem Duodenalsaft, spezifische Aktivität $690 \mathrm{U} / \mathrm{mg}\left(25^{\circ} \mathrm{C}\right)$ gegen Triolein als Substrat.

„Lipase-Standard“" (Sollwert $452 \mathrm{U} / \mathrm{l}$ ), aus der Testpackung Lipase, turbidimetrischer Test, Boehringer Mannheim, Bestell-Nr. 263346.

Esterase (Carboxylester hydrolase, EC 3.1.1.1), aus Schweineleber, Boehringer Mannheim, Bestell-Nr. 104 698, spezifische Aktivität etwa $100 \mathrm{U} / \mathrm{mg}\left(25^{\circ} \mathrm{C}\right)$ gegen Buttersäureethylester als Substrat.

Ein Teil der Kristallsuspension wurde bei $+4{ }^{\circ} \mathrm{C}$ gegen physiologische $\mathrm{NaCl}$-Lösung dialysiert.

Cholinesterase (Acylcholin acyl hydrolase, EC 3.1.1.8), aus Humanplasma, Boehringer Mannheim, Bestell-Nr. 348643 , spezifische Aktivität $9 \mathrm{U} / \mathrm{mg}\left(25^{\circ} \mathrm{C}\right)$ gegen Butyrylthiocholiniodid als Substrat. 


\section{Probenmaterial}

Bei den verwendeten Proben handelte es sich um:

Seren von Gesunden,

Seren von Patienten mit akuten oder chronischen Pankreaserkrankungen,

Seren, die etwa 10 Minuten nach i.v. Injektion von 5000 I.E. Heparin von Gesunden gewonnen wurden,

Seren, in denen die Pankreaslipase durch zweistïndige Inkubation bei $56^{\circ} \mathrm{C}$ vollständig inaktiviert worden war; dies wurde im titrimetrischen Test mit Triolein als Substrat nachgewiesen.

\section{Reagentien}

Für die Messungen der katalytischen Aktivität der Enzyme wurde die im Handel befindliche Reagentien-Kombination (Testomar ${ }^{\circledR}$-Lipase Combipack) der Behringwerke, Marburg, verwendet. Als Endkonzentration im Test werden angegeben:

$\begin{array}{lcl}\text { Vinyl-8-phenyloctanoat } & 13 & \mathrm{mmol} / \mathrm{l} \\ \text { Bicin } & 48 & \mathrm{mmol} / \mathrm{l} \\ \text { Natriumdesoxycholat } & 21 & \mathrm{mmol} / \mathrm{l} \\ \text { Kaliumchlorid } & 2,9 & \mathrm{~mol} / 1 \\ \text { NADH } & 0,19 \mathrm{mmol} / 1 \\ \text { Alkoholdehydrogenase } & 17 & \mathrm{kU} / 1\end{array}$

Der pH-Wert beträgt 8,0 .

Angaben des Herstellers zu Art und Konzentration der verwendeten Tenside fehlen. Es ist jedoch anzunehmen, daß entsprechend den Vorschlägen von Myrick (4) zusätzlich Triton X-100 und Triton X-305 im Testansatz enthalten sind.

Die Auflösung der Reagentien erfolgte nach Vorschrift.

Als Esterase-Hemmstoff diente Phenylmethylsulfonylfluorid krist., Boehringer Mannheim, Bestell-Nr. 236608 . Unmittelbar vor Gebrauch wurde die Substanz in Propanol-2 gelöst und diese Lösung mit physiologischer $\mathrm{NaCl}$-Lösung so verdünnt, daß eine Endkonzentration von $1,5 \mathrm{mmol} / 1$ in wäßriger Propanol-2 $(100 \mathrm{ml} / \mathrm{l})$-Lösung vorlag. Lösungen mit geringeren Konzentrationen des Hemmstoffs wurden durch Verdünnen dieser Stammlösung mit Propanol-2 (100 ml/1) in physiologischer $\mathrm{NaCl}$ Lösung hergestellt. Die untersuchten Proben wurden mit den Hemmstofflösungen unterschiedlich lange bei $25^{\circ} \mathrm{C}$ vorinkubiert und aliquote Teile dieser Mischungen in den Test mit Vinyl-8-phenyloctanoat eingesetzt. Als Kontrollen verwendeten wir Proben, die mit hemmstoffreier Propanol-2-Verdünnung inkubiert worden waren.

\section{Methodik}

\section{Prinzip}

Der von Myrick (4) beschriebenen Methode zur Bestimmung der katalytischen Aktivität von Lipase liegen folgende Reaktionen zugrunde:

Vinyl-8-phenyloctanoat $+\mathrm{H}_{2} \mathrm{O} \stackrel{\text { Lipase }}{\longrightarrow}$ 8-Phenyloctansäure + Vinylalkohol

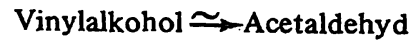

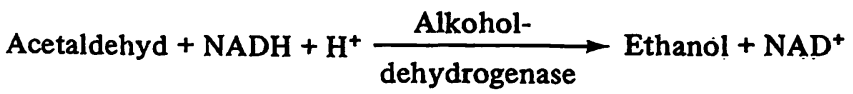

Meßgröße ist die durch den Verbrauch an NADH bedingte Absorptionsabnahme.

\section{Ausführung}

Um Vergleiche mit anderen Bestimmungsmethoden zu ermọglichen, wurden die Messungen bei $25^{\circ} \mathrm{C}$ ausgefuihrt.

$\mathrm{Da}$ die Substrat-Tensid-Lösung stark viskös ist, lassen sich kleine Volumina nicht ausreichend exakt abmessen. Abweichend von der Originalvorschrift wurde daher für eine Bestimmungsserie jeweils ein Enzym-Coenżym-Puffer-Substrat-
Gemisch hergestellt. In Vergleichsuntersuchungen zeigte sich, daß dieses Reagens mindestens 3 Stunden haltbar ist.

Das infolge der hohen Tensidkonżentration technisch schwierige und zeitraubende Mischen der Ansätze in einer mit Parafilm verschlossenen Küvette ließ sich auf folgende Weise vermeiden: Die Temperierung von jeweils $2,2 \mathrm{ml}$ Gemisch auf $25^{\circ} \mathrm{C}$ erfolgte in Reagensröhrchen. Nach Zugabe von $100 \mu l$ Probe, sorgfältigem Mischen unter Vermeidung von Schaumbildung und Uberführen des Ansatzes in eine Küvette im auf $25^{\circ} \mathrm{C}$ temperierten Küvettenhalter wurde die Absorption bei $365 \mathrm{~nm}$ im Spektrallinienphotometer (Eppendorf Digitalphotometer 6115) in Minutenabständen gemessen. In jeder Serie wurden Reagentien-Leerwerte mit bidest. Wasser und Kontrollen mit Enzymstandard anstelle der Probe angesetzt.

\section{Berechnung}

Soweit sich ein annähernd geradliniger Abșorptionsabfall ergab, wurde das durchschnittliche $\Delta \mathrm{A}$ pro Minute um den ReagentienLeerwert korrigièrt und die katalytische Aktivitätt wie folğt berechnet:

kạtaly țische Aktivität $=\Delta A_{365} \mathrm{~nm} / \operatorname{minn} \cdot 6765(\underline{U} / \mathrm{l})$.

\section{Ergebnisse}

\section{Reagentien-Leerwert}

Mit den von uns verwendeten Reagentien-Chargen wurde ein Absorptionsabfall beobachtet, der 5-13 U/1 entsprach. Dabei ist zu berücksichtigen, daß zur exakten Messung so geringer Absorptionsdifferenzen besonders hohe Anforderungen an Stabilität und Auflösungssvermögen des $P$ hotometers gestellt werden müssen. Folgt man der Empfehlung, die Meßwerte kontinuierlich zu registrieren und benutżt man die routinemäßig übliche Spreizung der Absorption von 0 bis 0,500 auf dem Schreiber, so ist eine ausreichend genaue Beurteilung des chargenabhängigen Reagentien-Leètwerts nicht möglich. Über die zulässige Höhe des Reagentien-Leerwerts werden vom Hersteller keine Angaben gemacht.

\section{Inaktiviertes Serum}

Seit 1966 konnte an insgesamt 45 Poolseren im titrimetrischen Test mit Triolein als Substrat gezeigt werden, daß die Pankreaslipase nách 2-stündigẹr Inkubation bei $56^{\circ} \mathrm{C}$ vollständig inaktiviert ist. Diêse Tatsache wurde auch dadurch untermauert, daß bei Verdünnung von Seren hoher katalytischer Aktivität mit einer inaktivierten Serummischung untêr Vèrwendung optimaler Konzentrationen an Na-Glykocholat die gleichen Ergebnisse gefunden werden wie bei Verdünnung mit physiologischer $\mathrm{NaCl}$ - oder Humanalbuminlösung. Sètżte man das bèi $56{ }^{\circ} \mathrm{C}$ vorbehandelte Serum in den Test mit Vinyl-8phenyloctanoat ein, so ergaben sich über den ReagentienLeerwiwert hinausgehende Absorptionisändèrungen. Wäre eine Umrechnung in katalytische Konzentration gerechtfertigt, so enthielten die Seren ohne Abzug eines Reagentien-Leerwertes zwischen 24 und 27 U/1. Als. Erklärung sind zwei Möglichkeiten zu erwägen: Entweder wird in dem von Myrick beschriebenenen Test ein im Serum ent- 
haltenes, bei $56{ }^{\circ} \mathrm{C}$ nicht oder nicht vollständig inaktiviertes Enzym mitgemessen, das Triolein nicht umsetzt, oder es läuft eine andere NADH verbrauchende Reaktion mit einem der Serumbestandteile ab.

\section{Spezifität und Reaktionsablauf}

Unter den angegebenen Bedingungen wird Vinyl-8phenyloctanoat nicht nur von Pankreaslipase, sondern auch von Esterase, Cholinesterase und von der in Postheparinserum enthaltenen Lipoproteinlipase umgesetzt (s. Tab. 1). Mithin ist die Methode nicht spezifisch für Pankreaslipase.

Tab. 1. Katalytische Aktivitäten lipolytischer und esterolytischer Enzyme gegenüber verschiedenen Substraten.

\begin{tabular}{lcccc}
\hline & $\begin{array}{l}\text { Vinyl- } \\
\text { 8-phenyl- } \\
\text { octanoat }\end{array}$ & Triolein & $\begin{array}{l}\text { Tween } \\
20\end{array}$ & $\begin{array}{l}\text { 1-Mono- } \\
\text { olein }\end{array}$ \\
\hline $\begin{array}{l}\text { Gereinigte Pankreas- } \\
\text { lipase, EC 3.1.1.3 } \\
\text { (U/mg) }\end{array}$ & 39,5 & 690 & 0 & 0 \\
$\begin{array}{l}\text { Carboxylesterase } \\
\text { aus Schweineleber, } \\
\text { dialysiert, EC 3.1.1.1 } \\
\text { (U/mg) }\end{array}$ & 10,9 & 0 & 47,5 & 0,35 \\
$\begin{array}{l}\text { Cholinesterase } \\
\text { aus Humanplasma }\end{array}$ & 0,014 & 0 & - & - \\
$\begin{array}{l}\text { EC 3.1.1.8 } \\
\text { (U/mg) }\end{array}$ & & & & \\
$\begin{array}{l}\text { Postheparinserum } \\
\text { (U/1) }\end{array}$ & 407 & 280 & 1450 & 320 \\
\hline
\end{tabular}

Während bei Einsatz von gereinigter Lipase, Esterase, Cholinesterase und den meisten Postheparinseren in einem bestimmten Konżentrationsbereich ein geradliniger Reaktionsablauf beobachtet wurde, fiel die Absorption nur bei einem Teil der untersuchten Seren linear ab (s. Tab. 2). Bei den übrigen Proben verlief die Indikatorreaktion unabhängig von der Höhe der katalytischen Aktivität und vom èingesetzten Probevolumen nicht geradlinig (s. Tab: 3). Bei dièsen Serên ist eine Auswer: tung nach der angegebenen Vorschrift nicht möglich: Die Ursache dieser Störung, die auf den Eigenschaften der Probe beruht, ist nicht bekannt.

Tab. 2. Beispiele für geradlinigen Reaktionsablauf im kontinuierlichen Test mit Vinyl-8-phenyloctanóat als Substrat $(\Delta \mathrm{A} / \mathrm{min})$.

\begin{tabular}{lllllll}
\hline $\begin{array}{l}\text { Zeit } \\
\text { nach } \\
\text { Start } \\
\text { (min) }\end{array}$ & $\begin{array}{l}\text { gerei- } \\
\text { nigte } \\
\text { Lipase }\end{array}$ & $\begin{array}{l}\text { Ester } \\
\text { asề }\end{array}$ & $\begin{array}{l}\text { Ester- } \\
\text { ase }\end{array}$ & $\begin{array}{l}\text { Cholin- Post- } \\
\text { esterase }\end{array}$ & $\begin{array}{l}\text { Peparin- } \\
\text { serum }\end{array}$ & $\begin{array}{l}\text { Pañea- } \\
\text { titis- } \\
\text { serum 19 }\end{array}$ \\
\hline & & & & & & \\
\hline & 0,022 & 0,036 & 0,164 & 0,022 & 0,061 & 0,085 \\
3 & 0,021 & 0,035 & 0,166 & 0,022 & 0,064 & 0,085 \\
4 & 0,023 & 0,034 & 0,162 & 0,022 & 0,062 & 0,085 \\
5 & 0,022 & 0,036 & 0,163 & 0,021 & 0,063 & 0,085 \\
6 & 0,021 & 0,036 & 0,165 & 0,022 & 0,063 & 0,082 \\
7 & 0,022 & 0,035 & & 0,021 & 0,062 & 0,086 \\
8 & 0,022 & 0,036 & & 0,022 & 0,063 & 0,083 \\
& 0,021 & 0,034 & & 0,021 & 0,063 & 0,085 \\
\hline
\end{tabular}

Tab. 3. Beispiele für nicht geradlinigen Reaktionsablauf im kontinuierlichen Test mit Vinyl-8-phenyloctanoat als Substrat $(\Delta A / \mathrm{min})$.

\begin{tabular}{|c|c|c|c|c|c|}
\hline $\begin{array}{l}\text { Zeit } \\
\text { nach } \\
\text { Start } \\
\text { (min) }\end{array}$ & $\begin{array}{l}\text { Serum } \\
\text { eines } \\
\text { Gesunden }\end{array}$ & $\begin{array}{l}\text { Pankreat } \\
100 \mu \mathrm{l} / \\
n \text { Test }\end{array}$ & $\begin{array}{l}\text { itisserun } \\
50 \mu \mathrm{l} / \\
\text { Test }\end{array}$ & $\begin{array}{l}7 \\
20 \mu 1 / \\
\text { Test }\end{array}$ & $\begin{array}{l}10 \mu \mathrm{l} / \\
\text { Test }\end{array}$ \\
\hline $\begin{array}{l}1 \\
2 \\
3 \\
4 \\
5 \\
6 \\
7 \\
8\end{array}$ & $\begin{array}{l}0,011 \\
0,009 \\
0,009 \\
0,007 \\
0,006 \\
0,007 \\
0,006 \\
0,005\end{array}$ & $\begin{array}{l}0,061 \\
0,058 \\
0,054 \\
0,051 \\
0,048 \\
0,047 \\
0,046 \\
0,044\end{array}$ & $\begin{array}{l}0,040 \\
0,036 \\
0,031 \\
0,027 \\
0,025 \\
0,024 \\
0,023 \\
0,021\end{array}$ & $\begin{array}{l}0,019 \\
0,016 \\
0,015 \\
0,013 \\
0,012 \\
0,011 \\
0,011 \\
0,010\end{array}$ & $\begin{array}{l}0,010 \\
0,008 \\
0,008 \\
0,007 \\
0,006 \\
0,006 \\
0,006 \\
0,005\end{array}$ \\
\hline
\end{tabular}

Setzt man reine Enzyme in den Test ein, so ergibt sich ein gerad'iniger Zusammenhang zwischen Enzymmenge im Test und Absorptionsabfall in einem weiten Bereich bis zu einer katalytischen Aktivität von mindestens $1000 \mathrm{U} / 1$.

\section{Versuche zur Erhöhung der Spezifität}

Turini et al. (5) konnten zeigen, daß Phenylmethylsulfonylfluorid die katalytische Aktivität der Acetylcholinesterase aus menschlichen Erythrocyten hemmt.

Daher versuchten wir, die Spezifität des Tests für Pankreaslipase durch Vorinkubation der Proben mit diesem Hemmstoff zu erhöhen. Da die Substanz nur in AlkoholWasser-Mischungen löslich ist, wurde der Test mit Vinyl8-phenyloctanoat auf Beeinflussung durch Mischungen von Propanol-2 und physiologischer $\mathrm{NaCl}$-Lösung ohne bzw. mit Inhibitor geprüft. Auch in Abwesenheit esteround lipolytischer Enzyme ergaben sich Absorptionsabbzw. -zunahmen in Abhängigkeit von der zugefügten Menge an verdünntem Propanol-2, während Phenylmethylsulfonylfluorid selbst keine weitere Änderung bewirkte (s. Tab. 4).

Tab. 4. Kontinuierlicher Test mit Vinyl-8-phenyloctanoat. Änderung der Absorption bei $365 \mathrm{~nm}$ nach Zusatz von Propanol-2 (100 ml/1 physiologische $\mathrm{NaCl}-\mathrm{L}$ ösung) ohne und mit Phenylmethylsulfonylfluorid $(1,5 \mathrm{mmol} / \mathrm{l})$.

\begin{tabular}{|c|c|c|}
\hline \multirow{2}{*}{$\begin{array}{l}\mu l \\
\text { Propanol-2 } \\
(100 \mathrm{ml} / \mathrm{l}) \\
\text { im Test }\end{array}$} & \multicolumn{2}{|c|}{ Absorptionsänderung pro 5 Minuten } \\
\hline & $\begin{array}{l}\text { ohne Phenyl- } \\
\text { methylsulfonyl- } \\
\text { fluorid }\end{array}$ & $\begin{array}{l}\text { mit } 1,5 \mathrm{mmol} / 1 \text { Phenyl- } \\
\text { methylsulfonylfluorid }\end{array}$ \\
\hline $\begin{array}{c}1,25 \\
3,12 \\
6,25 \\
12,5 \\
20 \\
25 \\
50 \\
100\end{array}$ & $\begin{array}{l}-0,009 \\
-0,005 \\
-0,002 \\
+0,004 \\
+0,011 \\
+0,013 \\
+0,024 \\
+0,037\end{array}$ & $\begin{array}{l}-0,009 \\
-0,005 \\
-0,002 \\
+0,002 \\
+0,011 \\
+0,013 \\
+0,024 \\
+0,036\end{array}$ \\
\hline
\end{tabular}

- = Absorptionsabfall pro 5 Minuten (Mittelwert) + = Absorptionsanstieg pro 5 Minuten (Mittelwert)

Die angegebenen $\mathrm{Absorptionsdifferenzen} \mathrm{entsprechen} \mathrm{den} \mathrm{reinen}$ Meßwerten, d.h. sind nicht um einen Reagentien-Leerwert korrigiert. 
Die katalytische Aktivität der Leberesterase wurde bereits durch 5 Minuten lange Inkubation mit Phenylmethylsulfonylfluorid in einer Endkonzentration von $0,1 \mathrm{mmol} / 1$ weitgehend gehemmt (s. Abb. 1). Unter den Versuchsbedingungen befanden sich im Testansatz 6,25 $\mu$ l Propanol-2-(100 ml/1)-Lösung. Bei dieser Propanol-2-Konzentration ist die nicht enzymbedingte Absorptionsänderung pro Zeiteinheit praktisch zu vernachlässigen (s. Tab. 4). Eine Erhöhung der Inhibitorkonzentration auf das Vierfache ergab nur eine geringgradig stärkere Hemmung. Ähnliche Befunde wurden von Turini et al. (5) an der Acetylcholinesterase erhoben. Da Phenylmethylsulfonylfluorid in höheren Konzentrationen aus Propanol-2-Wasser-Mischungen ausfällt und Propanol-2 nicht in höheren Konzentrationen in den Test eingesetzt werden kann, ist eine vollständige Hemmung der Leberesterase mit diesem Inhibitor in einer praktikablen Inkubationszeit nicht möglich.

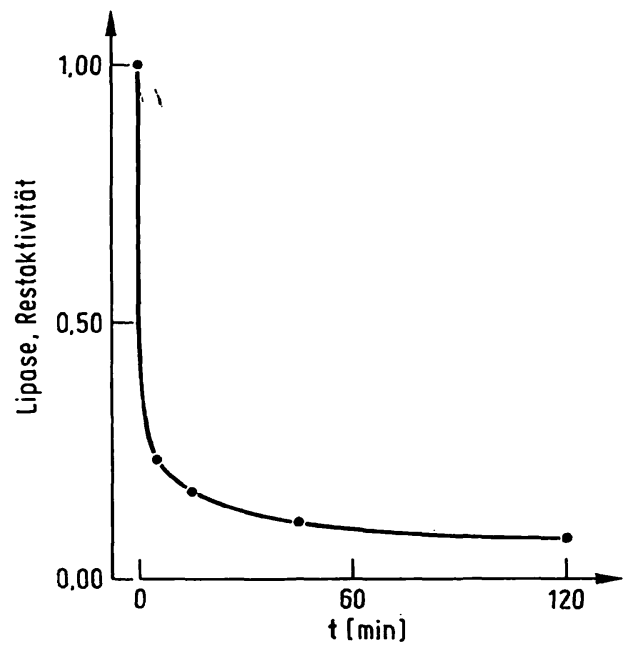

Abb. 1. Kontinuierlicher Test mit Vinyl-8-phenyloctanoat. Hemmung der Schweineleberesterase durch Phenylmethylsulfonylfluorid $(0,1 \mathrm{mmol} / 1)$ in Abhängigkeit von der Inkubationszeit.

In analoger Weise läßt sich auch die Cholinesteraseaktivität durch Phenylmethylsulfonylfluorid hemmen. Da die spezifische Aktivität der Cholinesterase gering ist, wirkten sich die Absorptionsänderungen von ReagentienLeerwert und Propanol-2-Konzentration im Test prozentual so stark aus, daß die Hemmung nicht ausreichend genau quantifiziert werden konnte.

Bei Seren von Gesunden und bei einem Teil der Seren von Patienten mit Pankreaserkrankungen war aufgrund der unbefriedigenden Kinetik im Test mit Vinyl-8-phenyloctanoat eine Interpretation der Ergebnisse ohne und mit Phenylmethylsulfonylfluorid nicht zuverlässig möglich. Bei den übrigen Proben von Pankreatitispatienten ergaben sich mit Phenylmethylsulfonylfluorid Aktivitätsminderungen um 10-20\%.

Die Spaltung des Substrats durch Postheparinserum war nach Vorinkubation mit $0,1 \mathrm{mmol} / 1$ Phenylmethylsulfonylfluorid um 20-30\% gehemmt.

\section{Vergleichsuntersuchungen}

Zur Prüfung der diagnostischen Aussagekraft des kontinuierlichen Verfahrens mit Vinyl-8-phenyloctanoat als Substrat führten wir Vergleichsuntersuchungen mit dem titrimetrischen Test al's Referenzmethode aus. Die im folgenden angegebenen Daten stellen Mittelwerte aus Doppelbis Vierfächbestimmungen dar. In jeder Serie wurde zur Qualitätskontrolle die Lipase-Präparation (Sollwert 452 U/1) mitgeführt, die beim turbidimetrischen Test nach Ziegenhorn et al. (6) als Bezugsstandard verwendet wird. Bei der Titrimetrie betrug der Variationskoeffiżient (VK) von Tag zu Tag 2,5\% $(\mathrm{n}=25)$, beim UV-Test nach Myrick 3,1\% $(\mathrm{n}=13)$.

An 102 Seren, bèi denen trotz des nicht ausreichend linearen Reaktionsablaufes im UV-Test überhaupt eine Auswertung gerechtfertigt erschien, fanden sich die in Abbildung 2 gezeigten Ergebnisse. Bei der Darstellung

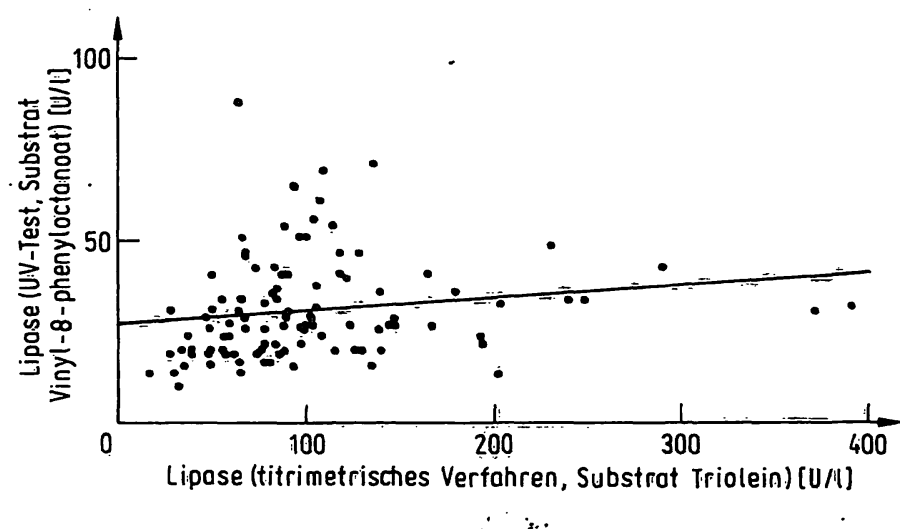

Abb. 2. Vergleichsuntersuchungen des ÜV-Tests nach Myrick mit dem titrimetrischen Test an 102 Seren. $y=27,9+0,034 x ; r=0,158$

wurde entsprechend den Literaturangäben über die obêre Grenze des Referenzbereichs beim UV-Test von $70 \mathrm{U} / 1$ und beim titrimetrischen Verfahren von 140 U/1 (2) der Máßstab so gewählt, daß đie Regrèssionsgerade einen Winkel von $45^{\circ}$ mit der Abszisse bilden müßte, wenn mit beiden Substraten das gleiche Enżym bestimmt würde. Die Gleichung der Regressionsgeraden lautet jedoch: $y=27,9+0,034 x$; eine Korrelation der Meßwerte ist nicht gegeben $(r=0,158)$. Mithin besteht kein Zusammenhang zwischen den Ergebnissen beider Me= thoden. Dies wird auch aus Tabelle 5 deutlich, in der Seren mit erhöhten katalytischen Aktivitäten gegenüber Triolein zusammengestellt sind. In den meisten Fällen wururde Vinyl-8-phenyloctanoat nicht vermehrt umgesetżt. Bei den sehr hohen katalytischen Aktivitäten gegenüber Triolein ist die Spaltung von Vinyl-8-phenyloctanoat nur relativ geringgradig erhộht. Auch hier wird eine konstante Relation vermißt. .: 
Tab. 5. Ergebnisse von Seren mit erhöhter katalytischer Aktivität an Lipase.

\begin{tabular}{|c|c|}
\hline $\begin{array}{l}\text { Titrimetrischer Test mit } \\
\text { Triolein als Substrat } \\
\text { (Referenzbereich bis } 140 \mathrm{U} / 1 \text { ) }\end{array}$ & $\begin{array}{l}\text { UV-Test mit } \\
\text { Vinyl-8-phenyloctanoat als } \\
\text { Substrat } \\
\text { (Referenzbereich bis } 70 \mathrm{U} / 1 \text { ) }\end{array}$ \\
\hline $\begin{array}{r}193 \mathrm{U} / 1 \\
248 \mathrm{U} / 1 \\
179 \mathrm{U} / 1 \\
290 \mathrm{U} / 1 \\
371 \mathrm{U} / 1 \\
239 \mathrm{U} / 1 \\
391 \mathrm{U} / 1 \\
203 \mathrm{U} / 1 \\
192 \mathrm{U} / 1 \\
230 \mathrm{U} / 1 \\
201 \mathrm{U} / 1 \\
295 \mathrm{U} / 1 \\
435 \mathrm{U} / 1 \\
11000 \mathrm{U} / 1 \\
6000 \mathrm{U} / 1 \\
13200 \mathrm{U} / 1\end{array}$ & $\begin{array}{r}22 \mathrm{U} / 1 \\
34 \mathrm{U} / 1 \\
36 \mathrm{U} / 1 \\
43 \mathrm{U} / 1 \\
31 \mathrm{U} / 1 \\
34 \mathrm{U} / 1 \\
32 \mathrm{U} / 1 \\
33 \mathrm{U} / 1 \\
24 \mathrm{U} / 1 \\
49 \mathrm{U} / 1 \\
14 \mathrm{U} / 1 \\
56 \mathrm{U} / 1 \\
45 \mathrm{U} / 1 \\
350 \mathrm{U} / 1 \\
540 \mathrm{U} / 1 \\
1420 \mathrm{U} / 1\end{array}$ \\
\hline
\end{tabular}

\section{Diskussion}

Bei der Ausführung des von Myrick (4) zur Bestimmung der Lipase beschriebenen Tests treten zahlreiche Probleme auf.

Nebenreaktionen verursachen einen höheren Absorptionsabfall bei Einsatz von inaktiviertem Serum im Vergleich zu Leerwerten mit bidest. Wasser.

Auffällig ist weiterhin, daß sich bei Seren und Kontrollproben mit serumähnlichen Eigenschaften häufig ein nichtlinearer Ablauf der Indikatorreaktion ergibt, der eine Auswertung erșchwert oder unmöglich macht, während mit reinen Enzymen oder Kontrollproben mit Serumalbumin als Stabilisator eine geradlinige Kinetik gefunden wird. Die erwähnten Störungen müssen daher durch die Eigenschaften der Proben bedingt sein. Der Vorschlag von Kornmüller \& Müller-Plathe (7), Störungen infolge der Probeneigenschaften durch einen ProbenLeerwert zu beseitigen, in dem das Hilfsenżym inakti= viert wurde, führt nach Untersuchungen von Beck-Oostendorp et al. (8) nicht zum Erfolg, da bei der Mehrzahl der Proben Trübungen auftreten.

Die Meßreaktion hängt nach Angaben des Herstellers nur geringfuigig von der Inkubationstemperatur ab. Myrick gibt außerdem an, dạ sich die Reaktionsgeschwindigkeit zwischen $\mathrm{pH}$ 7,0 und 9,0 kaum ändert. Als Ursache für beide Beobachtungen sind die hohe Tensidkonzentration im Testansatz und die Unspezifität dẹ Reaktion zu diskutieren.

Aus den vori Myrick angegebenen Daten geht bereits hervor, daß Schweineleberesterase unter den Bedingungen des Tests nicht vollständig gehemmt ist (Abb. 3 aus 1.c. (4)). Dies entspricht den in Tabelle 1 dargestellten Befunden. Weiterhin wird das Substrat. mit hoher Geschwindigkeit von Lipoproteinlipase gespalten. Stein et al. (9) fanden eine Korrelation zwischen der katalytischen Aktivität der Cholinesterase im Serum und der gleichzeitig gegen Vinyl-8. phenyloctanoat gemessenen. Wie wir zeigen konnten, setzt auch reine Cholinesterase das Substrat um. Junge et al. (10) identifizierten in Extrakten aus menschlichem Pankreas eine Esterase, die Vinyl-8-phenyloctanoat, nicht aber Triolein umsetzt. Mithin wird der von Myrick empfohlene Ester von einer Reihe von Enzymen gespalten, so daß er kein spezifisches Substrat zur Bestimmung der Pankreaslipase darstellt.

Die Unspezifität des Verfahrens nach Myrick geht auch aus folgendem hervor: Während das Verhältnis der katalytischen Aktivitäten gegenüber Vinyl-8phenyloctanoat bzw. Triolein bei reiner Pankreaslipase 39,5:690 oder 1:17 beträgt (s. Tab. 1), liegen die oberen Grenzen der Referenzbereiche bei $70 \mathrm{bzw} .140 \mathrm{U} / 1$. Aus dieser Relation von 1:2 ist ebenfalls zu schließen, daß die katalytischen Aktivitäten gegenüber dem von Myrick beschriebenen Substrat dadurch relativ erhöht sind, daß neben Pankreaslipase auch eine Reihe won Esterasen mitgemessen wird.

Aufgrund der Tatsache, daß nicht nur Leberesterase, sondern auch andere Enzyme das von Myrick empfohlene Vinyl-8-phenyloctanoat hydrolysieren, ist es verständlich, daß Versuche von Junge \& Leybold (11), die Methode durch Zugabe von Bis- $p$-nitrophenylphosphat - einem Inhibitor der Carboxylesterase aus menschlicher Leber - zu verbessern, nicht zu einer wesentlichen Erhöhung der Spezifität geführt haben.

Eigene Versuche zeigen, daß auch Phenylmethylsulfonylfluorid, das in niedrigen Konzentrationen die Aktivität reiner Esterasen stark herabsetzt, die im Serum enthaltenen störenden Enzyme kaum beeinflußt. Dem Zusatz höherer Konzentrationen des Inhibitors sind allerdings dadurch Grenzen gesetzt, daß die Meßreaktion durch das als Lösungsvermittler notwendige Propanol-2 gestört wird.

Infolge der Unspezifität der Methode von Myrick (4) ist ihre klinische Aussagekraft stark eingeschränkt. Stein et al. (9) fanden normale kataly tische Aktivitäten gegenüber Vinyl-8-phenyloctanoat in Seren, deren Lipase mit Triolein als Substrat bis auf $700 \mathrm{U} / 1$ erhöht war. Andererseits ergaben sich eine Reihe falsch pathologischer Befunde im UV-Test. In den von uns ausgeführten Vergleichsuntersuchungen an 102 Seren zeigte sich keine Korrelation zwischen den Ergebnissen der Titration mit Triolein als Substrat und dem UV-Test $(r=0,158)$ (Abb. 2). Bei Seren mit mäßig erhöhter Lipase wurde gegenüber Vinyl-8-phenyloctanoat ein im Referenzbereich liegender Umsatz gefunden; erst bei sehr hohen katalytischen Aktivitäten im titrimetrischen Test (79-, 45- bzw. 94-faches der oberen Grenze des Referenzbereiches) ergaben sich pathologische Resultate im UV-Test, die jedoch nur das 5-, 8- und 20fache der oberen Grenze des Referenzbereiches darstellten. 


\section{Literatur}

1. Marchis-Mouren, G., Sarda, L. \& Desnuelle, P. (1959) Arch. Biochem. Biophys. 83, 309-319.

2. Rick, W. (1969) Z. Klin. Chem. Klin. Biochem. 7, 530-539.

3. Rick, W. (1976) Lipase. In: Forell, M. M. (Hrsg.), Handbuch der Inneren Medizin, 5. Aufl., Bd. III/6: Pankreas. Springer, Berlin.

4. Myrick, J. E. (1976) A spectrophotometric method for the kinetic measurement of lipase activity. Ph. D. Dissertation. Birmingham, Ala.

5. Turini, P., Kurooka, S., Steer, M., Carbascio, A. N. \& Singer, T. P. (1969) J. Pharmacol. Exp. Therap. 167, 98-104.
6. Ziegenhorn, J., Neumann, U., Knitsch, K. W. \& Zwez, W. (1979) Clin. Chem. 25, 1067.

7. Kommüller, K. J. \& Müller-Plathe, O. (1978) Ärzti. Lab. 24, 363-371.

8. Beck-Oostendorp, E., Köchli, H. P., Degiampietro, P. \& Colombo, J. P. (1981) Med. Lab. 34, 77-82.

9. Stein, W., Liebich, H. M., Locher, M., Mildner, A. \& Ludwig, U. (1979) J. Clin. Chem. Clin. Biochem. 17, 653-656.

10. Junge, W., Leybold, K. \& Philipp, B. (1979) Clin. Chim. Acta 94, 109-114.

11. Junge, W. \& Leỹbold, K. (1977) Lab. Med. I, 149-150.

Prof. Dr. W. Rick

Institut für Klinische Chemie und Laboratoriumsdiagnostik der Univerșität Düsșeldorf

Moorenstraße $\overline{5}$

D-4000 Düsseldorf 1 